\title{
Mining Business Risk Management
}

\author{
Olena Kozyrieva ${ }^{1, *}$, Veronika Khudolei $^{2}$, Valentina Vyhovska $^{3}$, Maksym Zabashtanskyi ${ }^{3}$, \\ and Andrii Rogovyi ${ }^{3}$ \\ ${ }^{1}$ National University of Pharmacy, 61057, 53 Pyshkinskaya street, Kharkiv, Ukraine \\ ${ }^{2}$ Academician Yuriy Bugay International Scientific and Technical University, 026603 \\ Magnitogorsky ln., Kyiv, Ukraine \\ ${ }^{3}$ Chernihiv National University of Technology, 14035, 95 Shevchenko str., Chernihiv, Ukraine
}

\begin{abstract}
In the mining industry, as a dangerous industry related to the specifics of its production, in particular, the process of risk management and analysis should be taken into account. One of the main reasons of occupational accidents, in addition to human error and technical failures, is the lack of foresight of possible accidental events, and the lack of assessment by a company of the risks associated with occupational safety. The article considers the main risks in the mining industry, analyses the problems of modern systems of risk assessment and management of mining investment projects, methods and sequence of qualitative and quantitative risk assessment, provides recommendations for their improvement in order to bring them in line with international risk management standards.
\end{abstract}

\section{Introduction}

The emergence of rapidly developing digital technologies, the growth of regulatory pressure and global economic uncertainty are key risk factors that are inherent in any sector of the national economy, including mining.

Although risks are constantly present in the mining industry, they have not been studied sufficiently in practical terms. Currently, the risk management system for geological and mining projects is carried out according to the traditional scheme for assessing project financial risks, often without taking into account the geological features of the subsoil, mining technology and specific mining law.

Nevertheless, information on identification, classification, qualitative and quantitative risk assessment in exploration and exploitation of deposits has always been in demand in the feasibility study of geological and mining projects.

The tasks of identifying, classifying and managing risks are not reduced to the development of measures to evade them, but require introduction of systems aimed at the interaction of risk subjects with their sources, identification of the causes of risk situations, and determination of behaviour when specific risks emerge.

\footnotetext{
*Corresponding author: yakakos74@gmail.com
} 
A quantitative assessment of parametric risks and a qualitative characteristic of nonparametric risks of the mining industry create the basis for risk management systems for geological and mining projects, which is also one of the most urgent management tasks.

Solving the problems of identification, classification and creation of risk management systems will ensure the efficient functioning of the national mining industry, overcome the consequences of the permanent crisis of the Russian economy, and also carry out planning in the face of the global trend of growing uncertainty and risks.

\section{Results and Discussion}

The on-going active development of raw materials in the mining industries of Russia has led to almost complete exhaustion of the previously created reserve of explored deposits. As a result, the owners of the mining business are forced to acquire the right to use the subsoil of deposits and plots located at the earliest stages of geological exploration, that is, to operate in conditions of high uncertainty of decisions made.

It is obvious that during mining operations the depth of mining in Russia increases, the conditions of mining are complicated, what inevitably leads to a constant increase in the complexity of mining and transportation of rocks, lowering the productivity of transport and mining equipment and increase of the cost of production.

A prerequisite for the active development of risk management and, in particular, risk research in our country was the accident at the Chernobyl NPP, after which there was a crisis in the system of views on safety and risk problems. In the future, a methodology for quantitative risk assessment developed for nuclear energy has become increasingly used in other areas of human activity. However, at the present stage, methods of quantitative assessment cannot yet cover the whole wide range of hazard factors.

Mining enterprises, in accordance with the accepted classification, as well as nuclear power facilities are classified as potentially hazardous facilities (VET). At the same time, economic activity on the development of mineral deposits has a specific feature. The mineral resource base of a mining company is both an environment for carrying out economic activities (an object of risk) and at the same time a risk factor.

The subsoil user, possessing, likewise his colleagues in other types of business, the entirety of information about the facilities, machines, mechanisms and technologies at his disposal, at the same time never possesses the entirety of knowledge about the structure of the subsoil within which he carries out his activities. This leads to the emergence of a continuous additional risk factor, which is usually referred to as "mountain risk".

The basis for deciding on the feasibility of developing a deposit is geological data obtained on the basis of exploratory wells drilled on a specific grid. As a result, the constructed geological models of deposits have one or another level of error, moreover, it is variable at different points of the bowels.

Experience shows that the impact of mountain risk on the economic activities of mining enterprises is very significant. Thus, the low reliability of the obtained geological data led in the 90s to the forced termination of the construction of the Anzherskaya-Yuzhnaya mine. The volume of waste installation work amounted to RUB 2 billion. A similar fate befell the Shcherbinovsky open pit in 2000 - mining operations after the commissioning of the open pit were discontinued with the amount of attracted investments for the purchase of mining equipment at RUB 60 million.

When carrying out mining activities, in addition to mountain risk, there are other risks associated with the mineral resource base. In particular, there is the risk of losing market share due to a biased assessment of mineral reserves from a market position.

In international practice, to make a decision on investing in a particular mining company and to predict the market capacity of various minerals, data are used on the 
volume of reserves, which, according to the Russian classification. belong to category A and $\mathrm{B}$ reserves. In Russian practice, when assessing provision with reserves, the mineral resources of categories $\mathrm{P} 1$ and $\mathrm{P} 2$ are also taken into consideration, as a result, the data on the actual volumes of reserves provided to the market are overestimated [1].

From the point of view of the specifics of the mining industry, it is possible to single out the risks that arise in the mining industry that significantly affect the discovery, preparation and operation of deposits, as well as other related processes carried out directly in mines:

- geological risk (amount of resources, quality of resources, mineralogical composition, availability of resources);

- technological risk (technology of work in the field, the possibility or impossibility of extraction and processing, hazardous natural phenomena, the specificity of operations planned);

- economic and financial risk (transaction costs, inability to accurately determine demand, market competition, interest rates, exchange rates, inflation);

- political risk (the possibility of privatization, changes in legislation and regulations, such as income tax, environmental protection provisions);

- risks associated with ensuring occupational safety [2].

It is worth mentioning, that over the past few years, the structure of business risks has changed dramatically: out of the key risks of 2009, only three (social production license, resource nationalism and access to energy) continue to be in top ten $[3,4]$.

Over the past year alone, when reassessing the economic situation, a significant change occurred in the structure key risks position.

So, in accordance with the analysis, the key risk factors for the mining industry are as follows:

- market instability, lower prices for goods and rising product balances result;

- risks arising from the need to reduce costs and changes in exchange rates;

- inability to complete or integrate acquired and joint ventures into current operations or manage asset sales;

- difficulties with project management and the effectiveness of investment in new projects in remote regions;

- slowdown in China and increased independence in consumer goods production;

- the growth of geopolitical risks in the Middle East, North Africa and Eastern Europe, which impede the activities and implementation of the strategies of global companies;

- difficulties with capital allocation and risk management of changes in company strategies;

- fierce market competition for limited natural resources between companies and stakeholders;

- difficulties in obtaining a social license obliging to comply with strict, often changing laws in the field of sustainable development and environmental protection;

- increase in the cost of maintaining / restoring the image of a socially responsible company;

- reputation, operational and regulatory risks associated with incidents in labour protection, industrial safety and environmental protection;

- risks associated with large investments in research and development of new technologies for the use of robotics and $\mathrm{AI}$ in mining;

- the interaction of various IT and operating platforms, protocols and techniques that lead to an increase in cyber risks, such as interruption of systems and cyber security violations;

- interruption or damage to production due to natural disasters, outages of water or electricity supply or extreme weather conditions;

- credit risks, liquidity restrictions and refinancing risks;

- exposure to the risk of corruption and fraud resulting from activities in various jurisdictions and politically unstable regions; 
- prolonged strikes in key mining regions;

- an ineffective asset management strategy and inaccurate calculations of existing and potential reserves lead to interruption of activity and its inefficiency [5].

The identification, calculation and analysis of risk factors is the key to the success of the project.

The ISO 31000 (2009) risk management standard recommends organizations to create risk management frameworks to integrate risk management processes into management structures, strategic planning, reporting systems, policies, values and culture. The risk management process entails the systematic application of policies and procedures, methods and practices for actions that are aimed at communication, analyses and identification of risks. Risk management framework is a mechanism that offers the basis and structures for the design, creation, monitoring, analysis and continuous improvement of risk assessment at an enterprise.

The standard proposes principles or values of risk management and schematically demonstrates how they are connected with the blocks related to communication and consultation, establishing context, monitoring and analysis [6-9].

The establishment of communications and consultations with external and internal sources based on the requirements of the Standard should be carried out and relate to all stages in the enterprise risk management process. It is important that communication and consultation facilitate the exchange of information characterized as reliable, important, accurate and understandable information [10-12].

When establishing the context, a mining company should clearly state its goals, determine the external and internal parameters adopted in the future risk management process, and establish a distribution zone and risk criteria for the remaining processes.

Risk management should be seen as a dynamic rather than a statistical set of actions. The correct implementation of the risk management cycle should begin at the source and become part of an interactive process that helps to take decisions.

For the risk associated with the resource, it is extremely important that the risk becomes an integral part of the processes, and the enterprise implement the risk management system. Risk qualification is critical to decision making, and various methods are available for this purpose. Some of the available quantitative methods for assessing resource risks are as follows [13]:

- sensitivity analysis assesses the sensitivity of results (e.g. NPV) to changes in input data, such as capital costs, grade, throughput, operating costs, commodity prices and macroeconomic indicators such as inflation and exchange rates;

- classical statistical methods used to predict and evaluate probable estimates at points that are not selected;

Monte Carlo simulation predicts likely results by randomly changing input values. Monte Carlo simulation creates a probability distribution for the potential risks associated with the investment, and therefore realistic results can be visualized. The accuracy of Monte Carlo simulations depends on a truly representative resource model, realistic estimates, and well-defined analysis goals [14];

- conditional modelling assumes that the use of resources is spatial and temporal. The methodology develops or predicts how a deposit can vary in terms of tonnage and class using 3D-modeled reality models. Conditional modelling produces probable variations of resources and, thus, illustrates the risk at the source;

- DCF models are used to evaluate the rate of return and the net present values of a project or competing projects and are used as the basis for decision making. To demonstrate project risk levels, some practitioners include a factor in the discount rate of the DCF model. The discount rate will include such aspects as a risk-free interest rate, the risk of mineral projects (represents the numerous risks associated with the resource) and the risk of the 
county (represents political risk, policies and management problems in the host country for the project) [15];

- analysis / evaluation of real options (modern methods of asset pricing), methods recognize that management has the ability to change project results through decision making and the ability to determine opportunities. Unlike DCF, which involves a passive path, real-life options analysis or modern asset pricing methods recognize management flexibility in decision making [16].

Risk assessment includes risk identification, risk analysis and assessment (quantitative).

However, mining enterprises do not pay necessary attention to the analysis and assessment of project risks. Most of the mining enterprises currently do not take measures aimed at risk management, there is no so-called systematic approach, which often leads not only to the impossibility of the project, but also to the shutdown of the entire enterprise.

The process of managing the risks of a mining enterprise itself is as follows. Questionnaires are filled in, risk factors that can affect the project are determined, the probability of the occurrence of this event and the "weight" of risk, other words, the possible damage from implementation are determined. The following step are the actions to manipulate this risk. All the filled questionnaires are sent to the department at the enterprise engaged in risk management, which collects and analyses all the information from different departments, as a result, identifying more serious risks. [17-19]

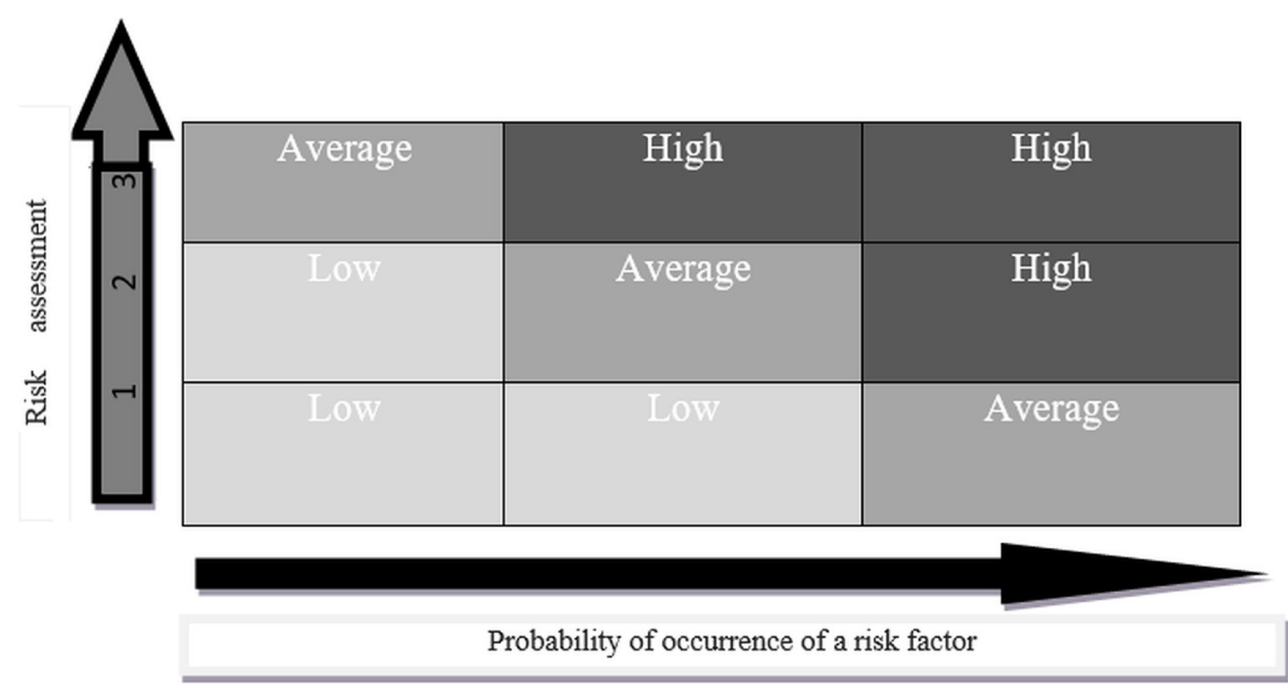

Fig. 1. Risk map of enterprise.

The approach considered, as can be seen from the description, is based solely on qualitative methods of risk analysis and does not provide a correct assessment of risks in its entirety and can lead to losses at the enterprise, therefore it is much more correct and more rational to use comprehensive measures to ensure a correct risk assessment.

Let's consider the basic methods for assessing (analysing) risks in a mining enterprise (Table 1).

Thus, it can be concluded that the use of a system that includes a set of quantitative and qualitative methods in order to get an accurate assessment of all risks that affect the enterprise is to be considered best possible solution. 


\section{Conclusion}

Thus, risk management is the most important tool of the management system of a modern mining company and the formation of strategies for the functioning and development of facilities that are sources of increased danger.

Table. 1. Methods of project risks assessment.

\begin{tabular}{|l|l|}
\hline \multicolumn{1}{|c|}{ Quality assessment } & \multicolumn{1}{c|}{ Quantitative assessment } \\
\hline $\begin{array}{l}\text { Consideration and analysis of all risks in the } \\
\text { enterprise. A quantitative assessment of the } \\
\text { probability, the magnitude of the possible } \\
\text { damage to the enterprise and the degree of } \\
\text { resistance to various risks. }\end{array}$ & $\begin{array}{l}\text { A quantitative assessment of the likelihood, the } \\
\text { magnitude of possible damage to the enterprise } \\
\text { and the degree of resistance to various risks. }\end{array}$ \\
\hline $\begin{array}{l}\text { Determining the causes of their occurrence and } \\
\text { developing measures to reduce the impact of } \\
\text { risks. }\end{array}$ & $\begin{array}{l}\text { Due to the use of this analysis, it is possible to } \\
\text { more accurately and as close as possible to } \\
\text { reality assess the probability of occurrence of } \\
\text { adverse events, calculate the damage from them, } \\
\text { trough the use of mathematical techniques, } \\
\text { probability theory. }\end{array}$ \\
\hline $\begin{array}{l}\text { Determination of the probability and degree of } \\
\text { exposure to risks by expert method. }\end{array}$ &
\end{tabular}

An analysis of the economic development of mining enterprises shows that the effectiveness of a business is determined by the ability to correctly and accurately assess the likelihood of adverse effects in each specific field of activity and the consequences (scale) of possible undesirable events. Successful organizations achieve results due to their ability to find the optimal balance of risks and benefits, both strategically and tactically.

What is clear is that for the sustainable growth of value, the mining sector requires more than just high financial results. In order to regain confidence in the industry, companies need to completely change their reputation, focusing on environmentally friendly and customer-oriented strategies based on advanced technologies.

\section{References}

1. S.A. Abdel, Modelling financial risk in open pit mine projects: implications for strategic decision-making (SAI of MM, London, 2008)

2. O. Bertoli, S. Jackson, J. Vann, An overview of Geostatistical Simulation for Quantifying Risk (Geostatistical Assotiation of Australasia, Melbourn, 2012)

3. M. McKelvey, G. Buenstorf, A. Broström, Innovation: Organization \& Management, 20:1, 84 (2018)

4. M. P. Davies, Potential problem analysis: A practical risk assessment technique for the mining industry (Mineral Economics Society of CIM, London, 2007)

5. J. C.Westland, Global Innovation Management: A Strategic Approach (Macmillan International Higher Education, New York, 2008)

6. C. E. Dohm Application of simulation techniques for combined risk assessment of both geological and grade model-an example (SAI of MM, London, 2013)

7. E. Hoffecker. Local Innovation: what it is and why it matters for developing economies. D-Lab Working Papers: NDIR Working Paper 01 (Massachusetts Institute of Technology, Cambridge, 2018)

8. O. Granstrand, M. Holgersson, Technovation, 90, 91 (2020) 
9. G. Xu, Y. Wu, T. Minshall, Y. Zhou, Technological Forecasting and Social Change, 136, 208 (2018)

10. D.J. Isenberg and V. Onyemah, Innovations: Technology, Governance, Globalization, 11:1-2, 60 (2016)

11. T. Haines, Technology Innovation Management Review, 6:6, 24 (2016)

12. VCI Mining Innovation: State of Play 2015 Survey - Methodology (VCI, Melbourne, 2015)

13. H. Bathelt, P. Cohendet, S. Henn, L. Simon, The Elgar Companion to Innovation and Knowledge Creation (Edward Elgar Publishing Ltd, Liverpool, 2017)

14. R. Heurberger, Risk analysis in the mining industry (SAI of MM, London, 2015)

15. C. P. Jager, Risk Management in Mining and Minerals Economics as well as Mineral Resource Management (University of Witwatersrand, Witwatersrand, 2015)

16. A.S. Macfarlane, Mineral Resource Management and Risk in Mine Project Analysis (University of Witwatersrand, Witwatersrand, 2016)

17. O. Garafonova, E3S Web Conf., 41, 04006 (2018)

18. O. Garafonova, Y. Lazarenko., E3S Web Conf., 134, 03011 (2019)

19. O O. Garafonova, Y. Lazarenko., E3S Web Conf., 134, 04042 (2019) 